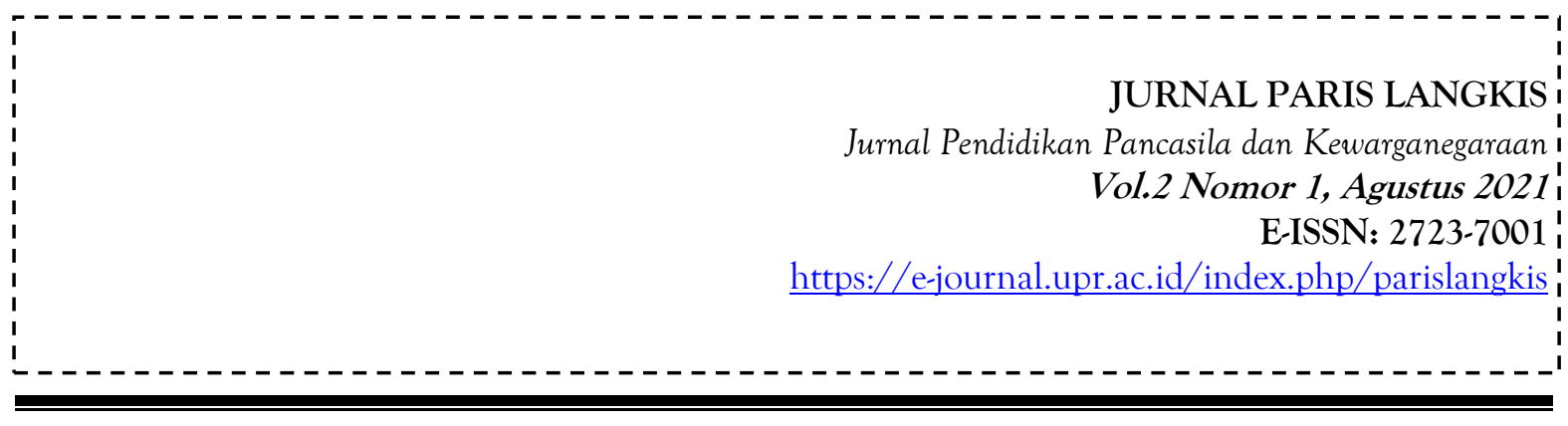

\title{
ANALISIS KRITIS PENDIDIKAN KARAKTER DALAM PEMBELAJARAN IPA TERPADU DAN KAITANNYA DENGAN MUTU PENDIDIKAN
}

\author{
Sanimah $^{1}$, Sri Wahyuni ${ }^{2}$ \\ ${ }^{1,2}$ STKIP Budidaya BinjaiJalan Gaharu, No.147, Jati Makmur, Binjai Utara, Sumatera Utara, \\ Indonesia \\ Email: ${ }^{1}$ Sanimah220989@gmail.com, ${ }^{2}$ yuni210984@gmail.com
}

\begin{abstract}
Abstrak
Penelitian ini membahas analisis kritis terhadap kondisi mutu pendidikan di Indonesia yang masih meprihatinkan, dimana kondisi ini memiliki hubungan dengan krisis karakter yang terjadi pada anak didik di Indonesia pada tahun belakangan. Salah satu upaya menanggulangi krisis karakter adalah melalui pendidikan karakter yang dapat diintegrasikan dalam pembelajaran. Penelitian ini bertujuan untuk menganalisis secara kritis bagaimana pendidikan karakter dalam pembelajaran IPA terpadu dapat menjadi solusi dalam meningkatkan mutu pendidikan di Indonesia. Penelitian ini menggunakan metode kualitatif dengan jenis deskriptif agar dapat menghasilkan deskriptif yang sistematis dan objketif mengenai fakta dan unsure yang ada dalam penelitian. Berdasarkan hasil analisis diperoleh bahwa Sesuai Kurikulum 2013 pembelajaran IPA di SMP tidak lagi berSifat disiplin ilmu melainkan integrative science atau terpadu. Perubahan kurikulum ini merupakan salah satu upaya pemerintah dalam meningkatkan mutu pendidikan. Melalui pembelajaran IPA secara terpadu pembelajaran tidak hanya terfokus pada kognitif melainkan juga pada skill dan sikap. Ketiga aspek ini merupakan komponen yang harus dimiliki siswa untuk dapat membentuk karakter baik pada siswa. Dengan terbentuknya karakter baik pada siswa diharapkan akan meningkatkan mutu pendidikan di Indonesia. Karena pembentukkan karakter yang baik pada anak merupakan tujuan dari pendidikan nasional dan ketercapaian tujuan pendidikan nasional merupakan tolak ukur mutu pendidikan.
\end{abstract}

Kata Kunci : Mutu Pendidikan; Kurikulum 2013; Pembelajaran IPA terpadu; Pendidikan karakter

\section{Paris Langkis}

Vol.2 Nomor 1, Agustus 2021 


\begin{abstract}
This study discusses a critical analysis about the condition of the quality from education in Indonesia, where this condition has a relationship with the character crisis that occurred in students in Indonesia in recent years. One effort to overcome the character crisis is through character education that can be integrated in learning. This study aims to critically analyze how character education in integrated science learning can be a solution in improving the quality of education in Indonesia. This study uses qualitative methods with descriptive type in order to produce systematic and objective descriptive results about the facts and elements that exist in the study. Based on the results of the analysis, it was found that in accordance with the curriculum 2013, science learning in junior high school was no longer a scientific discipline, but rather integrative science. This curriculum change is one of the government's efforts to improve the quality of education. Through integrated science learning is not only focus on cognitive but also on skills and attitudes. These three aspects are components that must be possessed by students to be able to form good character in studying. The formation of good character in students is expected to improve the quality of education in Indonesia. Because the formation of good character in children is the goal of national education and the achievement of national education goals is a measure of the quality of education
\end{abstract}

Key word : education quality, curriculum 2013, integrated science, good character

\title{
A. PENDAHULUAN
}

Upaya peningkatan mutu pendidikan pada dasarnya terus dilakukan oleh berbagai pihak. Upaya-upaya tersebut dilandasi kesadaran pentingnya peran pendidikan untuk mengembangkan sumber daya manusia dan karakter bangsa (Nation Character Building) demi memajukan bangsaIndonesia. Karena harkat dan martabat suatu bangsa sangat ditentukan oleh kualitas pendidikannya, maka peningkatan mutu pendidikan melalui pembangunan di bidang pendidikan nasional merupakan bagian dari upaya peningkatan kualitas manusia Indonesia secara menyeluruh (Mulyasa, 2005:31).

Mengkaji tentang membangun karakter bangsa, pada hakikatnya tidak boleh terlepas dari tujuan Pendidikan Nasional yang memiliki landasan konseptual filosfi pendidikan untuk membebaskan dan menyiapkan generasi masa depan agar dapat bertahan hidup dalam menghadapi tantangan zaman.

Pendidikan karakter termasuk dalam salah satu tujuan Pendidikan Nasional. Tercantum dalam Pasal I Undang- Undang tentang Sistem Pendidikan Nasional Tahun 2003 menyatakan bahwa diantara tujuan Pendidikan Nasional adalah mengembangkan potensi peserta didik untuk memiliki kecerdasan, kepribadian dan akhlak mulia. Menurut pasal ini maka amanah Pendidikan Nasional tidak hanya membentuk insan Indonesia yang cerdas tetapi juga membentuk kepribadian dan akhlak mulia yang erat kaitannya dengan pembentukan karakter baik yang sesuai dengan nilai-nilai luhur bangsa Indonesia. Lebih lanjut disebutkan pada Pasal 3 Undang- Undang No.20 Tahun 2003 menyebutkan :

Pendidikan Nasional berfungsi mengembangkan kemampuan dan membentuk karakter serta peradaban bangsa yang bermartabat dalam rangka mencerdasan kehidupan bangsa. Pendidikan Nasional bertujuan memperkembangkan potensi peserta didik agar menjadi manusia beriman dan bertakwa kepada Tuhan Yang Maha Esa, berkahlak mulia, sehat,

\section{Paris Langkis}

Vol.2 Nomor 1, Agustus 2021 
berilmu, cakap, kreatif, mandiridan menjadi warga negara yang demokratis serta bertanggung jawab.

Berdasarkan isi pasal tersebut dijelaskan bahwa ada keterkaitan antara tujuan Pendidikan Nasional dengan pembentukan karakter peserta didik agar mampu bersaing, beretika, bermoral, sopan santun dan berinteraksi dalam masyarakat.Oleh karena itu, Pendidikan Nasional harus berfungsi secara optimal sebagai wahana utama dalam membangun karakter bangsa. Pendidikan karakter untuk mencapai tujuan pendidikan Nasionaldapat diimplementasikan dalam pembelajaran IPA.

Di dalam Pedoman Pengembangan Kurikulum 2013 disebutkan bahwa pembelajaran IPA di tingkat SMP dilaksanakan dengan keterpaduan. Pembelajaran IPA di SMP dikembangkan sebagai mata pelajaran integrative science bukan sebagai pendidikan disiplin ilmu. Maksudnya, pembelajran IPA berorientasi pada aplikatif, pengembangan kemampuan berpikir, rasa ingin tahu, dan pembangunan sikap peduli dan bertanggung jawab terhadap lingkungan alam dan sosial. Integrative scienceini mempunyai makna memadukan berbagai aspek yaitu sikap, pengetahuan, dan keterampilan. Ketiga aspek ini tercakup dalam satu kesatuan yaitu untuk membentuk karakter baik pada anak.

Akan tetapi pada tahun belakangan terjadi krisis karakter pada siswa di Indonesia, hal ini terlihat pada fenomena -fenomena berikut yang dikutip oleh Kesuma (2012:2-3), antara lain :

- Data hasil survey dengan sampel 33 provinsi di Indonesia pada tahun 2008 mengenai seks bebas di kalangan remaja Indonesia menunjukkan 63\% remaja Indonesia telah melakukan seks bebas.

- Data survey mengenai remaja korban narkoba menunjukkan ada 1,1 jua orang atau sekutar 3,9\% dari total jumlah sampel remaja di Indonesia telah menjadi korban narkoba .

- Data dari Pusat Pengendalian Gangguan Sosial DKI Jakarta menunjukkan pelajar SD, SMP, dan SMA, yang terlibat tawuran mencapai 0,08\% persen atau sekitar 1.318 siswa dari total 1.647 .835 siswa di DKI Jakarta. Bahkan, 26 siswa diantaranya meninggal dunia.

Melihat pada fenomena - fenomena tersebut maka terlihat jelas jawaban mengapa mutu pendidikan Indonesia masih sangat memperihatinkan. Kondisi mutu pendidikan Indonesia yang memprihatinkan ini dapat dilihat dari hasil studi kemampuan membaca untuk tingkat Sekolah Dasar (SD) yang dilaksanakan oleh Organisasi International Educational Achievement (IEA) yang menunjukan bahwa siswa SD di Indonesia berada pada urutan ke-38 negara peserta studi. Sementara untuk tingkat Sekolah Menegah Pertama (SMP), Studi utuk kemampuan Matematika siswa SMP di Indonesia hanya berada pada urutan ke - 39 dari 42 negara, dan untuk kemampuan Ilmu pengetahuan Alam (IPA) hanya berada pada urutan ke40 dari 42 negara peserta (Hamzah, 2009 : 134).

\section{Paris Langkis}

Vol.2 Nomor 1, Agustus 2021 
Fenomena - fenomena tersebut diindikasi berawal dari kegagalan dunia pendidikan dalam menjalankan fungsinya. Berangkat dari fenomena - fenomena tersebut maka diperoleh rumusan permasalahan antara lain :

- Penyebab krisis karakter pada siswa

- Solusi untuk menangani krisis karakter pada siswa

- Pentingnya pendidikan karakter dimasukkan dalam pembelajaran IPA terpadu di sekolah

- Pendidikan karakter berkontribusi meningkatkan mutu pendidikan

Berdasarkan latar belakang tersebut, maka akan dianalisis solusi alternatif untuk memecahkan masalah yang ada, sehingga saya mengambil judul "Analisis Kritis Pendidikan Karakter dalam Pembelajaran IPA Terpadu untuk Meningkatkan Mutu pendidikan."

\section{B. METODE}

Penelitian ini menggunakan metode kualitatif dengan jenis deskriptif agar dapat menghasilkan deskriptif yang sistematis dan objketif mengenai fakta dan unsur yang ada dalam penelitian maka dilakukan studi kepustakaan.

\section{HASIL DAN PEMBAHASAN}

1. Defenisi Pendidikan Karakter

David Elkind dan Freddy Sweet Ph.D memberikan defenisi pendidikan karakter:

"Character Education is deliberate effort to help people understand, care about, and upon core ethical values. When we think about the kind of character we want for our children, it is clear that we want them to be able to judge what is right, care deeply about what is right, and then do what they believe to be right, even in the face of pressure from without and temptation".

Menurut David Elkind dan Freddy Sweet Ph.D karakter seseorang dapat dibentuk dengan sengaja sesuai dengan keinginan,maka sangat dimungkinkan untuk membangun pendidikan karakter di sekolah yang dapat dirancang dalam pembelajaran sesuai dengan karakter yang diharapkann untuk dapat dimiliki anak didik.

Pendidikan karakter berhubungan erat dengan nilai-nilai, maka pendidikan karakter yag dibangun di sekolah harus sesuai dengan nilai-nilai bangsa Indonesia sehingga dapat tercapai tujuan Pendidikan Nasional.

\section{Nilai - Nilai dalam Karakter Bangsa Indonesia}

Karakter berasal dari nilai tentang sesuatu yang diwujudkan dalam bentuk perilaku anak (Kesuma,2012;11), jadi karakter sangat erat hubungannya dengan nilai. Ada banyak nilai yang dapat menjadi karakter , adapun nilai- nilai luhur bangsa Indonesia yang sesuai dengan karakter bangsa dapat dilihat pada Tabel 1 berikut :

\section{Paris Langkis}

Vol.2 Nomor 1, Agustus 2021 
Tabel 1. Nilai- nilai luhur bangsa Indonesia yang sesuai dengan karakter bangsa

\begin{tabular}{|c|c|c|}
\hline No & Nilai & Deskripsi \\
\hline 1 & Religius & $\begin{array}{l}\text { Sikap dan perilaku dalam melaksanakan ajaran agama yang dianut, toleran } \\
\text { terhadap agama lain. }\end{array}$ \\
\hline 2 & Jujur & Perilaku menjadikan dirinya sebagai orang yang dapat dipercaya. \\
\hline 3 & Toleransi & $\begin{array}{l}\text { menghargai perbedaan agama, suku, etnis, pendapat, sikap, dan tindakan } \\
\text { orang lain yang berbeda dari dirinya. }\end{array}$ \\
\hline 4 & Disiplin & tertiib dan patuh pada ketentuan dan aturan. \\
\hline 6 & Kreatif & menghasilkan cara atau hasil baru dari sesuatu yang telah dimiliki. \\
\hline 7 & $\begin{array}{l}\text { Demokrati } \\
\text { s }\end{array}$ & menilai sama hak dan kewajiban dirinya dan orang lain. \\
\hline 8 & $\begin{array}{l}\text { Rasa Ingin } \\
\text { Tahu }\end{array}$ & $\begin{array}{l}\text { selalu berupaya untuk mengetahui lebih mendalam dan meluas dari } \\
\text { sesuatu yang dipelajarinya, dilihat, dan didengar. }\end{array}$ \\
\hline 9 & $\begin{array}{l}\text { Cinta } \\
\text { Tanah Air }\end{array}$ & $\begin{array}{l}\text { menunjukkan kesetiaan, kepeduliaan, dan penghargaan yang tinggi } \\
\text { terhadap bahasa, lingkungan fisik, sosial, budaya, ekonomi, dan politik } \\
\text { bangsa. }\end{array}$ \\
\hline 10 & $\begin{array}{l}\text { Peduli } \\
\text { Lingkunga } \\
\mathrm{n}\end{array}$ & $\begin{array}{l}\text { mencegah kerusakan pada lingkungan alam di sekitarnya, dan } \\
\text { mengambangkan upaya-upaya untuk memperbaiki kerusakan alam yang } \\
\text { sudah terjadi. }\end{array}$ \\
\hline 11 & $\begin{array}{l}\text { Tanggung } \\
\text { Jawab }\end{array}$ & $\begin{array}{l}\text { melaksanakan tugas dan kewajibannya, yang seharusnya dia lakukan, } \\
\text { terhadap diri sendiri, masyarakat, lingkungan (alam, sosial dan budaya), } \\
\text { negara dan Tuhan Yang Maha Esa. }\end{array}$ \\
\hline
\end{tabular}

Sumber: Kementerian Pendidikan

Nasional, Pengembangan dan Pendidikan Budaya EF Karakter Bangsa: Pedoman Sekolah, 2009:9. 10

\section{Pembelajaran IPA Terpadu}

Pembelajaran IPA terpadu pada hakikatnya merupakan suatu pendekatan pembelajaran yang memungkinkan peserta didik baik secara individual maupun kelompok untuk aktif mencari, menggali, dan menemukan konsep serta prinsip secara holistik dan otentik (Depdikbud, 1996:3).

\section{Mutu Pendidikan}

Menurut Kamus Besar Bahasa Indonesia mutu adalah baik buruk suatu benda, kadar, taraf atau derajat misalnya kepandaian, kecerdasan dan sebagainya (Depdiknas, 2001:768). Secara umum kualitas atau mutu adalah gambaran dan karakteristik menyeluruh dari barang atau jasa yang menunjukkan kemampuannya dalam memuaskan kebutuhan yang diharapkan atau tersirat (Depdiknas, 2002:7).

\section{Paris Langkis}

Vol.2 Nomor 1, Agustus 2021 
Berdasarkan UU RI No. 20 Tahun 2003, tentang SISDIKNAS. Mutu pendidikan dapat dilihat dalam dua hal, yaitu pada proses pendidikan dan hasil pendidikan. Proses pendidikan bermutu apabila seluruh komponen pendidikan terlibat dalam proses pendidikan, meliputi berbagai input, seperti bahan ajar, metodologi, sarana sekolah,dukungan administrasi dan sarana prasarana dan sumber daya lainnya serta penciptaan suasana yang kondusif. Mutu dari hasil pendidikan dapa dilihat dari prestasi yang dicapai oleh sekolah pada kurun waktu tertentu.

\section{a. Penyebab Terjadinya Krisis Karakter}

Seperti yang telah disebutkan pada pendahuluan mengenai fenomena -fenomena krisis karakter yang terjadi di Indonesia pada tahun belakangan ini, maka untuk mencari solusi penanganannya kita lebih dahulu harus mengetahui apa saja yang menyebabkan terjadinya krisis karakter di Indonesia, antara lain :

- Berubahnyapemikiranmanusiayang lebih mementingkan keduniaan

- Lemahnya peranan keluarga dan sekolah sebagai wadah pembentukan karakter anak.

Dalam konteks ini kita membatasi pada sekolah sebagai wadah pembentukan karakter anak didik yang diharapkan dapat memberikan solusi guna mengatasi masalah krisis karakter pada anak didik.

\section{b. Membangun Karakter di Sekolah}

Dalam artikelnya Kimberly A. Vess \& Duane A. Halbur (2003) mengemukanan beberapa informasi tentang pendidikan karakter dari beberapa penelitian dan studi kasus:

"Character education is the "fastest growing reform movement in P-12 education today" (Williams, 2000, p. 32), thus all counselor educators and

counseling students need to be informed and cognizant of various P-12 character education programs. Currently, more than 30 states mandate some aspect of character education (Otten, 2000) and school counselors are frequently responsible for introducing character education curricula to their schools. However, research suggests that counselor education programs are not emphasizing character education in their preparation programs (Ryan $\mathcal{E}$ Bohlin,1999)".

Vess \& Duane A. Halbur mengemukakan bahwa Pendidikan karakteradalah gerakan reformasi yang tumbuhtercepat pada pendidikan saat ini. Saat ini, lebih dari30negara memiliki mandat untuk mengembangkan beberapa aspekpendidikan karakter. Hal ini menunjukkan bahwa pendidikan karakter pentimg untuk dibangun di sekolah.

Menurut Rohman (2012:62), membangun karakter bagi anak adalah menjadikan seorang anak terbiasa untuk berperilaku baik, sehingga ia menjadi terbiasa dan merasa bersalah kalau tidak melakukannya. Pendidikan karakter bagi anak adalah solusi untuk dapat mengubah perilaku negatif menjadi positif. Maka dari itu dalam membangun karakter baik pada anak diperlukan adanya lingkungan yang kondusif. Adapun dalam upaya membangun pendidikan karakter di sekolah dapat dilakukan dengan cara pembentukan budaya sekolah, yaitu nilai-nilai yang melandasi perilaku, tradisi, kebiasaan keseharian dan simbol-simbol

\section{Paris Langkis}

Vol.2 Nomor 1, Agustus 2021 
yang dipraktikkan oleh semua warga sekolah dan masyarakat sekitar sekolah (Amri,dkk,2011:31). Pembentukan budaya ini dapat dilakukan dengan mengitegrasikan pendidikan karakter melalui isi mata pelajaran dan proses pembelajaran. Dalam hal ini dibatasi pada pendidikan karakter melalui pembelajran IPA terpadu.

\section{c. Integrasi pembelajaran IPA Terpadu dalam Membangun Karakter}

Dalam artikelnya yang berjudul "Implementasi Pendidikan Karakter dalam Pembelajaran IPA (sains)", Wilujeng (2011) mengemukakan bahwa Pengembangan budaya karakter dapat dilakukan dengan beberapa strategi, antara lain integrasi dalam mata pelajaran IPA (Sains), pembiasaan dalam kehidupan keseharian di satuan pendidikan, integrasi ke dalam kegiatan ekstrakurikuler, penerapan pembiasaan kehidupan keseharian di rumah.

Khusus untuk integrasi dalam pembelajaran IPA dapat dilakukan dengan cara antara lain :

- Mengintegrasikan keterampilan-keterampilan berpikir dan strategi-strategi berpikir dalam aktivitas siswa. Apabila siswa sudah terlatih dengan keterampilan berpikir, strategi berpikir dan bernalar maka akan terbentuk siswa yang berkarakter, yaitu siswa yang mampumengintegrasikan pengetahuan, keterampilan-keterampilan dan sikapnya dalam usaha sehingga dapat memahami lingkungan.

- Melalui studi kasustentang isu-isu sains dan teknologi dalam masyarakat,. Dimana pengetahuan sains dan teknologi dibelajarkan dengan mengaplikasikan prinsipprinsip sains, teknologi serta dampaknya pada masyarakat dan lingkungan, sehingga akan memunculkan rasa peduli pada lingkungan dan menjunjung tinggi budaya, teknologi serta kearifan lokal.

- Melalui proses melatih menemukan konsep melalui kerja ilmiah. Metode ilmiah dapat melatih siswa untuk memiliki sikap ilmiah yang meliputi kejujuran, keterbukaan, rasa ingin tahu, tanggunf jawab,tekun, teliti, displin dan cermat.

Melihat dari ketiga integrasi ini makamenanamkan karakter yang baik pada siswa dapat diaplikasikan dalam pembelajaran IPA. Mengacu pada kurikulum 2013, di mana pembelajran IPA adalah pembelajaran yang terpadu bukan merupakan disiplin ilmu. Berdasarkan kurikulum 2013 integrasi pembelajran IPA terpadu terhadap kurikulum untuk membentuk karakter siswa dapat dilihat dari ;

- Pembelajaran IPA yang didasarkan pada standar isi akan membentuk siswa yang memiliki bekal ilmu pengetahuan (have a body of knowledge).

- Pembelajaran IPA yang didasarkan pada standar proses akan membentuk siswa yang memiliki keterampilan ilmiah (scientific skills), keterampilan berpikir (thinking skills) dan strategi berpikir (strategy of thinking).

- Pembelajran IPA yang didasarkan padastandar inkuiri ilmiah akan membentuk siswa yang mampu berpikir kritis dan kreatif (critical and creative thinking) .

Paris Langkis

Vol.2 Nomor 1, Agustus 2021 
- Pembelajaran IPA yang didasarkan pada standar asesmen mengevaluasi siswa secara manusiawi artinya sesuai apa yang dialami siswa dalam pembelajaran (authentic assessment).

Penerapan standar-standar dalam pembelajaran IPA seperti yang disebutkan di atas akan membentuk karakter siswa. Maka dapat disimpulkan bahwa siswa yang berkarakter dapat dicirikan apabila siswa memiliki kemampuan mengintegrasikan pengetahuan, keterampilan-keterampilan dan sikapnya. Kemampuan mengintegrasikan ini dapat dicapai siswa melalui pembelajaran IPA secara terpadu.

\section{d. Kontrubusi Pendidikan Karakter dalam Meningkatkan Mutu Pendidikan}

Beberapa upaya sudah dilakukan oleh pemerintah untuk meningkatkan mutu pendidikan di Indonesia, diantaranya proyek MPMBS (Manajemen Peningkatan Mutu Berbasis Sekolah), Proyek Perpustakaan, Proyek BOMM (Proyek Bantuan Meningkatkan Manajemen Mutu), Proyek BIS (Bantuan Imbal Swadaya), Proyek Peningkatan Mutu Guru, Proyek Pengadaan Buku Paket, Proyek DBL (Dana Bantuan Langsung), BOS (Bantuan Operasional Sekolah), dan BKM (Bantuan Khusus Murid), dan yang paling santer akhirakhir ini adalah merubah atau memperbaiki kurikulum.

Membatasi pada upaya peningkatan mutu pendidikan melalui perubahan kurikulum. Orientasi Kurikulum 2013 adalah terjadinya peningkatan dan keseimbangan antara kompetensi sikap (attitude), keterampilan (skill) dan pengetahuan (knowledge). Hal ini sejalan dengan amanat UU No. 20 Tahun 2003 pada Pasal 35:

" Kompetensi lulusan merupakan kualifikasi kemampuan lulusan yang mencakup sikap, pengetahuan, dan keterampilan sesuai dengan standar nasional yang telah disepakati. Hal ini sejalan pula dengan pengembangan kurikulum berbasis kompetensi yang telah dirintis pada tahun 2004 dengan mencakup kompetensi sikap, pengetahuan, dan keterampilan secara terpadu."

Adapun sejumlah hal yang menjadi alasan pengembangan Kurikulum 2013 antara lain :

- Adanya tantangan di masa depan diantaranya arus globalisasi, masalah lingkungan hidup, dan kemajuan teknologi informasi.

- Adanya kompetensi di masa depan diantaranya kemampuan berkomunikasi, kemampuan berpikir jernih dan kritis, kemampuan mempertimbangkan segi moral dalam suatu permasalahan,kemampuan menjadi warga negara yang efektif, dan kemampuan mencoba untuk mengerti dan toleran terhadap pandangan yang berbeda.

- Adanya fenomena sosial tentang krisis karakter yang mengemuka seperti yang disebutan pada pendahuluan.

- Persepsi masyarakat tentang pendidikan yang menganggap bahwa pendidikan selama ini terlalu menitikberatkan pada aspek kognitif, beban siswa yang terlalu berat, dan kurang bermuatan karakter sehingga terjadilah krisis karakter.

\section{Paris Langkis}

Vol.2 Nomor 1, Agustus 2021 
Berdasarkan uraian tersebut dapat dikatakan bahwa Kurikulum 2013 sebagai salah satu upaya untuk meningkatkan mutu pendidikan pada tujuannya bermuara pada pembentukan karakter baik pada anak didik. Karena fungsi dari kurikulum adalah untuk mencapai tujuan pendidikan, dan tujuan Pendidikan Nasional adalah untuk menciptakan anak didik yang memiliki karkater bangsa sesuai dengan nilai - nilai yang harus dimiliki oleh seluruh bangsa Indonesia, maka dalam hal ini pendidikan karakter berkontribusi dalam upaya untuk meningkatkan mutu pendidikan demi tercapainya tujuan Pendidikan Nasional.

\section{KESIMPULAN}

Adapun kesimpulan yang dapat diambil dari analisis kritis ini sesuai dengan permasalahan yang dirumuskan dalam pendahuluan antara lain :

- Salah satu penyebab krisis karakter pada siswa adalah karena sekolah belum Mampu menjalankan perannya untuk dapat membangun karakter anak didik

- Adapun Solusi untuk menangani krisis karakter pada siswa salah satunya dapat dilakukan dengan mengitegrasikan pendidikan karakter dalam pembelajaran dan mata pelajaran.

- Mengintegrasikan pendidikan karakter ke dalam pembelajaran IPA terpadu merupakan salah satu upaya untuk dapat membangun karakter anak melalui tiga aspek yaitu kognitif, keterampilan, dan sikap, sesuai dengan tujuan yang diharapkan pada kurikulum 2013.

- Dengan terbangunnya karakter baik pada anak maka akan tercapailah peningkatan mutu pendidikan.Karena pembentukkan karakter yang baik pada anak merupakan tujuan dari pendidikan nasional. Ketercapaian tujuan pendidikan nasional merupakan tolak ukur mutu pendidikan.

\section{E. SARAN}

Adapun saran untuk mengenbangkan pendidikan karakter dalam pembelajaran IPA terpadu untuk meningkatkan mutu pendidikan, antara lain :

- Melalui pembelajaran IPA terpadu berbasis lingkungan sehingga siswa dapat lebih arif dan bijaksana dalam memahami lingkungan dan bermasyarakat

- Melalui pembelajran IPA berbasis praktikum sehingga akan terbangun karakter berupa kejujuran, keterbukaan, rasa ingin tahu, tanggun jawab,tekun, teliti, displin dan cermat pada pribadi siswa.

\section{DAFTAR PUSTAKA}

Amri, Sofan, dkk. 2011. Implementasi Pendidikan Karakter dalam Pembelajaran.Jakarta : Prestasi Pustaka.

B. uno, Hamzah. 2009. Profesi kependidikan . Jakarta: Bumi Aksara.

Departement Pendidikan dan Kebudayaan, Pembelajaran IPA terpadu, 1996:3

\section{Paris Langkis}

Vol.2 Nomor 1, Agustus 2021 
Departemen Pendidikan Nasional, 2002, Manajemen Peningkatan Mutu Berbasis Sekolah Konsep Dasar, Jakarta : Ditjend Pendidikan Dasar dan Menengah, Ditjen SLTP.

Halbur,Duane A \& Kimberly A. Vess.. 2003. Character Education: What Counselor Educators Need to Know.University of North Carolina at Greensboro,: ERIC

Kesuma, Darma, dkk. 2012. Pendidikan Karakter. Bandung: Rosdakarya.

Kementerian Pendidikan Nasional, Pengembangan dan Pendidikan Budaya $\mathcal{E}$ Karakter Bangsa: Pedoman Sekolah, 2009: 9-10

Mulyasa E., 2005.Menjadi Kepala Sekolah Profesional, dalam Menyukseskan MBS dan KBK, Bandung : PT Remaja Rosdakarya.

Rohman, Muhammad. 2012.Kurikulum Berkarakter.Jakarta : Pertasi Pustaka

Wilujeng, Insih.2011. Implementasi Pendidikan Karakter dalam Pembelajaran IPA (sains). FMIPA UNY. 